\title{
The Effect of Organizational Culture on Employee Well- Being: Work- Related Stress, Employee Identification, Turnover Intention
}

\author{
Klajkó Dóra \\ University of Pécs, \\ Department of Social and Organizational Psychology \\ Restás Péter \\ University of Pécs, \\ Department of Social and Organizational Psychology \\ Szabó Zsolt Péter \\ Eötvös Loránd University, \\ Department of Social Psychology \\ Czibor Andrea \\ University of Pécs, \\ Department of Social and Organizational Psychology
}

\begin{abstract}
Direct and indirect costs of work-related stress can be measured in both humanistic and financial terms. In Hungary and the other Central and Eastern European countries chronic stress-related diseases, like depression, premature cardiovascular illnesses, and overall mortality rates are higher in comparison to western countries, primarily among men. The vast majority of the adult population is employed in some capacity and the average person spends more time working than in any other waking activity. Working conditions can exert influence on employee well-being. The present study aimed to explore the relationship between the perceived type of organizational culture (team, adhocracy, market, hierarchy) and employee well-being (perceived work-related stress, organizational identification, and turnover intention). Employees ( $N=256)$ from different Hungarian companies (Study 1) and employees ( $N=112)$ from Hungarian information technology firms (Study 2) completed a questionnaire battery measuring demographics, perceived organizational culture (OCAl), work-related stress (CSP), job satisfaction (JSS), and turnover intention (TIS-6). Our results show that the perceived organizational culture can significantly influence employees' well-being as reflected in their perceived stress level, turnover intention, and organizational identification. Our study is cross-sectional and explorative. Common method bias could overestimate the results due to the use of self-reported measures. Decreasing chronic stress factors and increasing employees' well-being are common objectives in the 21st century. In relation to these objectives, the present study provides information on employee well-being and optimal working conditions focusing on the fastest- growing industry.
\end{abstract}

Keywords: well-being, work-related stress, organizational culture, mental health, organizational identification, turnover intention, IT-industry 


\section{Journal of International Cooperation and Development}

www.richtmann.org/journal

Vol 2, No 2, November 2019

\section{Introduction}

Workplaces are important participants in society. Besides their economic importance, they influence several factors at an individual, community and society level. People spend most of their active time working (Aamondt, 2012); suitable physical, and social work environments, protective working conditions ensure adequate employee motivation and performance (Lamb et al., 2016; Renee, 2008), and the return on investments in health and safety at work is more than twice as much as the invested amount (International Social Security Association, 2013). These findings motivate modern companies to invest in employees' well-being. This motivation is particularly pronounced in industries such as information technology (IT) where the retention, motivation and satisfaction of employees with expertise and experience are key factors in long-term business success (Sageworks, 2016).

However, employees' well-being is a social issue as well. More than 300 million people suffer from depression globally (WHO, 2018). Considering health prospects in Eastern Europe and particularly in Hungary, all opportunities possibly improving wellbeing at a societal level should be exploited (Eurostat 2015).

The present study focused on protective factors related to organizational culture that influence employees' well-being at the workplace.

\subsection{Well-being}

The World Health Organization defines mental health as "a state of well-being in which every individual realizes his or her own potential, can cope with the normal stresses of life, can work productively and fruitfully, and is able to make a contribution to her or his community" (WHO, 2004). Conditions at the workplace such as basic hygiene factors (Herzberg, 2004), the quality of communication, information flow, social support, and having regard for individual abilities are closely related to the extent to which employees' experience that their workplaces meet the criteria set in the above definition. (Read and Lashinger, 2015; Kowalski et all., 2011)

Mental well-being poses one of the greatest challenges to societies in the 21st century. The European Union established priority areas in mental health and well-being in 2008, one of which areas is prevention and intervention at the workplace (European Commission, 2008).

Employee well-being is a multifaceted and fluid concept whose understanding largely varies across organizations and countries. Some of the factors that previous studies consistently found to be associated with workplace-related and personal wellbeing are value-based working environment and leadership style, open communication and dialogue, teamwork and cooperation, clear and coordinated objectives, flexibility, balance between business and personal life, and fair salary and benefits (Kraybill, 


\section{Journal of International Cooperation and Development}

www.richtmann.org/journal

Vol 2, No 2, November 2019

2003).A low level of perceived work- related stress, a high level of organizational identification, and a low level of turnover intention are among the most frequently applied criteria for employee well-being in the European Union (Buffet et al., 2013). The present study also used these measures as the indicators of employee well-being.

\subsection{Work-related stress}

Our first study focuses on employees' perceived stress, since the disproportionate mortality and comorbidity rates in Hungary are primarily attributed by several authors to chronic stress (Kopp et al., 2004, 2006). Indices of mental and physical well-being and mortality rates are worse than would be predicted by socio-economic factors. According to the 2015 Eurostat survey, the so-called Central-Eastern European health paradox is still observable. Several international research teams point out that chronic stress and mental or behavioural factors have essential importance in this phenomenon (Cornia \& Paniccià; Meslé, 2002; Weidner \& Cain, 2003; Meslé, 2004; Kopp et al., 2007). The related studies also draw attention to the direct importance of new forms of employment widespread in developed societies (WHO), and particularly to the importance of psychosocial factors. People are exposed to these effects in smaller and larger communities where they spend most of their time, and the workplace has primary importance in this respect.

In sum, work-related stress is a form of stress to which individuals are exposed at the organization or during work, and which impairs their quality of life and often leads to severe diseases or tragedies. There are diverse sources of stress at the workplace such as time pressure, lack of autonomy, role ambiguity, conflicts in cooperation, lack of supervisor's support, lack of appreciation (Toppinen-Tanner, 2011), and perceived instability and unpredictability of one's employment with an organization, that is, a high level of perceived job insecurity (Probst \& Lowler, 2006)

Findings reported by Kivimäki and Siegrist (2016) show that work-related stress may increase the risk and symptoms of cardiovascular disease and atherosclerosis over time. A significant relationship between job insecurity and coronary heart disease was revealed in a cohort study by Ferrie and colleagues (2013). In a similar vein, a comprehensive study by Kiss, Polonyi and Imrek (2018) points out the effects of chronic stress on physical and mental health and its relationship with the burnout syndrome. It is also worth considering the economic side of the problem, that is, the financial costs of an employee's health impairment. In a recent EU-funded project carried out by Matrix (2013), the costs work-related depression in Europe were estimated at $€ 617$ billion annually. The total amount included costs to employers resulting from absenteeism and presenteeism ( $€ 272$ billion), loss of productivity ( $€ 242$ billion), health care costs ( $€ 63$ billion), and social welfare costs of disability benefit payments ( $€ 39$ billion; European Agency for Safety and Health at Work, 2014). 


\section{Journal of International Cooperation and Development}

www.richtmann.org/journal

Vol 2, No 2, November 2019

\subsection{Organizational culture}

Workplace-related experiences of members of an organization are distilled into their perceived organizational culture. Organizational culture is a cohesive social force that supports internal integration and adaptation to the external environment (Daft, 2008). It is a shared system of beliefs and way of thinking established by the leaders and founders and accepted by all members of the organization (Klein, 2006). Hofstede (2008) uses the analogy of an operating system suggesting that culture as a software enables people to function as hardware. This is a dynamic interaction between the environment and the individuals. Employees construct a shared social reality in their interactions with colleagues at the workplace, which has an impact on their beliefs, emotion regulation and behaviour in certain situations. A stable organizational culture is based on a welldefined system of values (Schein, 2004). This system of values influences members' work style, communication and openness within the organization, their opportunities to foster community life and to realize their potential, and many other everyday organizational practices that have an impact on employees' well-being.

Numerous types of organizational culture models and several organizational culture assessment instruments have been proposed in the literature. One of the most commonly used organizational culture model is The Competing Values Framework (CVF, Quinn and Rohrbaugh, 1983). This model focuses on leadership styles, organizational cultures and competencies while taking account of employees' values. The objectives organizations pursue to increase efficiency and productivity are based on various values. The authors used the operating characteristics of efficient organizations to define the axes of the CVF. The vertical axis is defined by the two poles of flexibility and control, while the poles of the horizontal axis are internal and external focus. The two axes define four different types of cultures: team culture, adhocracy, market culture, and hierarchy.

Hierarchy is the earliest and most permanent type of culture, which is characterized by bureaucracy. It ensures predictability and security for employees, who are assigned well- defined specific roles. In this type of culture, employees are primarily expected to observe the rules and to have respect for formal positions. Hierarchy is placed on the controlled pole because employees are regularly supervised. The priorities of this type of culture are predictability, order, stability and balance, which are ensured by continuous documentation and stabilization. Leaders' primary functions are coordination and monitoring (Denison \& Spreitzer, 1991; OCAl online, 2012; Sherman et all., 2014)

A market culture considers the organization as an economic entity, which pursues rational interests and focuses on profits, productivity and efficiency. Employees have more autonomy and scope for personal development, while the tasks and objectives are clearly defined. This type of culture is also highly controlled but externally focused. Its priorities are productivity, efficiency and performance improvement. Leaders are directors on one hand, who fulfil a coordinating function, and producers on the other 


\section{Journal of International Cooperation and Development}

www.richtmann.org/journal

Vol 2, No 2, November 2019

hand, focusing on productivity.(Denison \& Spreitzer, 1991; OCAI online, 2012; Sherman et al., 2014)

A more recent development is the innovation-oriented adhocratic culture, which has taken a definite shape over the past decades. This type of culture usually develops in organic and open systems or at matrix organizations. Its primary advantage is its adaptability. It focuses on innovation, creativity and risk taking. Information flow is open in this culture, and members are motivated and supported rather than controlled. This culture is ideal for those with a strong need for personal development, since this is its highest priority. It is an externally focused and flexible culture, which often relies on external resources. Leaders themselves are also innovators or brokers. (Denison \& Spreitzer, 1991; OCAI online, 2012; Sherman et al., 2014)

A team culture focuses on human relations. This culture prioritizes agreement, coordination and teamwork. It assigns high importance to both commitment and personal development. Decision making is not leaders' sole responsibility, but other members are also involved and informed. This type of culture meets the needs for communion and learning. It is internally focused and flexible. Leaders are mentors and facilitators. (Denison \& Spreitzer, 1991; OCAI online, 2012; Sherman et all., 2014)

\subsection{Organizational culture and well-being}

The way employees perceive their work environment and organizational culture has essential importance in their well-being, health, and enjoyment and quality of work (Hellriegel \& Slocum, 1974; Kane-Urrabanzo, 2006). Employee well-being can be measured by factors such as sick leave rates, fatigue, and absenteeism (Peterson \& Wilson, 2002).

San Park and Hyun Kim (2009) examined how different types of organizational culture are associated with job satisfaction and turnover intention among hospital nurses in South Korea. Their findings highlight the impact of consensual culture, which had a significant positive association with nurses' job satisfaction. This type of culture is synonymous with the team culture in that it is centred around teamwork, and it lays special focus on the human condition and employees' problems. In addition, consensual culture exhibited the strongest, negative association with nurses' turnover intention, while hierarchical culture showed a significant positive association.

A case study of the Saudi Arabian banking sector explored the four organization culture types proposed by Cameron and Quinn (2002). The authors found that team culture showing the strongest correlation with job satisfaction followed by adhocracy, hierarchy and market culture (Aldhuwaihi, Shee, \& Stanton, 2012).

Janna (2016) explored which types of organizational culture were most closely related to variations in employees' work-related stress, self-perceived productivity, and enjoyment of work. Multivariate analyses showed that the type of organizational culture was significantly related to all dependent measures. Employees working in a team 


\section{Journal of International Cooperation and Development}

www.richtmann.org/journal

Vol 2, No 2, November 2019

culture reported the lowest levels of stress and the highest levels of productivity and enjoyment, followed by those working in adhocratic, hierarchical and market cultures.

Several studies suggest that one of the most important protective factors is the presence of social support, which is often associated with a team-oriented environment (La Rocco et al., 1980; Shortell et al., 2000; Glazer, 2001; Heaphy \& Dutton, 2008; Pow et al., 2017).

As we can see, workplaces have an important role and responsibility in ensuring the necessary conditions for well-being at a societal level. One the major components of the organizational experiences is the perceived organizational culture. The present study was aimed at identifying those organizational conditions that would act as protective factors against work-related stress through the organizational culture.

\section{Method}

The Organizational Psychology Research Team of the University of Pécs, Hungary examined the relation between organizational culture (team, adhocracy, market, hierarchy) and employee well-being along two studies.

\subsection{Study 1}

In the first study we conducted a study with 256 employees on the impact of organizational culture on employees' perceived stress. Considering that several studies focused on the impact of chronic stress and psychosocial risk factors on the prevalence of various health conditions in Hungary, the hypothesis of the present study was formulated as follows.

\subsubsection{Hypothesis}

S1H1: Organizational culture has an impact on the level of stress perceived by employees. Based on previous research (e.g. Janna, 2016) we predict that lowest levels of perceived stress will be found in Team cultures, while highest perceived stress levels will be characteristic for Hierarchy cultures.

\subsubsection{Sample}

A total of 256 employees from Hungarian companies participated in the study. Of the overall sample, $57.8 \% \quad(n=148)$ were males and $42.2 \% \quad(n=108)$ were females. Participants' age ranged from 20 to 65 years $(M=40)$. Tertiary education was completed by $24.5 \%$ and secondary education by $29.3 \%$. The majority of participants had a permanent residence in a town $(42.7 \%)$. 


\section{Journal of International Cooperation and Development}

www.richtmann.org/journal

Vol 2, No 2, November 2019

\subsubsection{Procedure}

An online questionnaire was administered to adult employees who were employed at the time of data collection.

\subsubsection{Instruments}

Participants completed an online questionnaire anonymously. They provided demographic data first, then they completed the Organizational Culture Assessment Instrument (OCAl; Cameron \& Quinn, 2002) and the Coping and Stress Profile (CSP) by Olson (1991).

The requested demographic data included participants' age, gender, employer and position at the company. Furthermore, participants provided information on how they acquired the skills and knowledge required for their jobs.

Organizational culture was measured with the Organizational Culture Assessment Instrument (OCAl) developed by Cameron and Quinn (2006), which is based on the authors' Competing Values Framework (Cameron \& Quinn, 1999). The OCAl is widely used in the business sector as well as by educational institutions and non-profit organizations. The OCAI identifies the values perceived as dominant at a specific organization. The questionnaire consists of 6 set of items, each set comprises 4 items, and each item within a set describes a specific type of culture. Respondents are requested to distribute 100 points among the four items on each dimension according to the extent to which they think each item applies to their workplace. The mean scores obtained for the four types of cultures (Team, Adhocracy, Market and Hierarchy cultures) are used to describe the culture of the specific organization. Team culture is described by ' $A$ ' items, adhocracy by ' $B$ ' items, market culture by ' $C$ ' items, and hierarchy by ' $D$ ' items. Characteristics of the four types of cultures are discussed in the introduction above.

Employees' perceived stress was assessed with the 28-item Work-related Stress Scale of the Coping and Stress Profile (CSP) by Olson (1991). The CSP is a self-report measure based on the theory of salutogenesis, that is, the measure provides information on respondents' well-being. Lower scores represent more adaptive coping strategies. Respondents rate each Likert item on a 5-point scale, and the sum of the item scores is calculated for each respondent.

\subsubsection{Results}

In accordance with the hypothesis, the statistical data analysis focused on possible differences between the above discussed four types of culture (team, adhocracy, market, hierarchy) in the average level of stress perceived by employees. The data were 
analysed with the IBM SPSS Statistics 20 software. Participants' scores on the OCAI were used to compute a variable for the dominant organizational culture, in which the four cultures were coded with four different values (team culture $=1$; adhocracy $=2$; market $=3$; hierarchy $=4$ ). Dominant organizational culture was entered in the statistical analysis as the independent (grouping) variable and total score for the CSP as the dependent variable. Since the four subsamples sorted under the four types of culture did not meet the assumption of homogeneity of variance (primarily because few participants perceived adhocracy as the dominant culture), the non-parametric equivalent of the one-way analysis of variance (ANOVA) was used to test the hypothesis. The results of the Kruskal-Wallis test showed that the four groups of employees' sorted by organizational culture perceived significantly different levels of stress $(F(3,256)=$ $6.834, p<.001)$, which confirmed the hypothesis.

The post hoc pairwise comparisons of the Kruskal-Wallis test indicated a significant difference in employees' perceived stress between the team $(M=62.98)$ and hierarchy cultures $(M=71.04, p=.001)$, and between the team and market cultures $(M=73.37, p$ $=.002)$

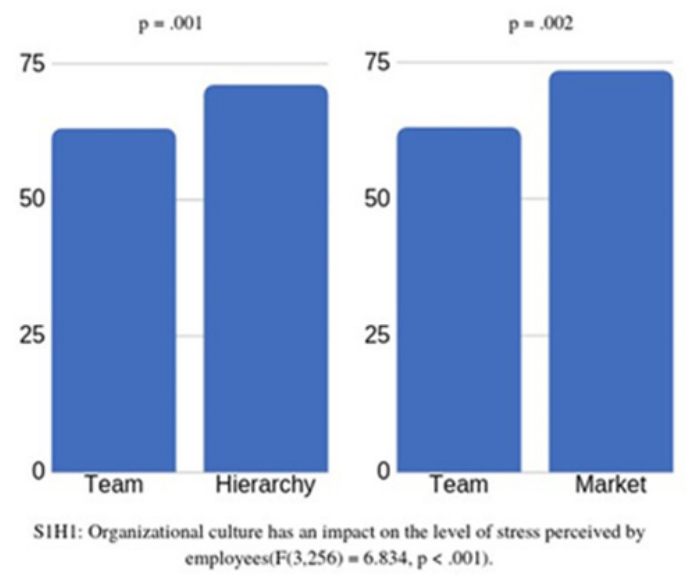

\begin{tabular}{|c|c|c|c|c|}
\hline $\begin{array}{c}\text { Culture } \\
\text { type (OCAI) }\end{array}$ & M SD & $\begin{array}{c}\text { Cronbach's } \\
\text { alpha }\end{array}$ & $\begin{array}{c}\text { Pearson's correlation } \\
\text { with perceived } \\
\text { stress (CSP) }\end{array}$ \\
\hline Team & 181.28 & 113.87 & .85 & $-.32^{* *}$ \\
\hline Adhocracy & 92.09 & 54.16 & .62 & -.12 \\
\hline Market & 124.51 & 98.99 & .85 & $.25^{* *}$ \\
\hline Hierarchy & 200.76 & 113.88 & .81 & $.16^{*}$ \\
\hline
\end{tabular}

1. Table Descriptive statistics, reliabilities and correlations between the variables in Study 1

Table 1 showes the decriptives, reliabilities and correlations between OCAI scales and perceived stress. Linear regression analyses were used to investigate how the scores on 


\section{Journal of International Cooperation and Development}

www.richtmann.org/journal

Vol 2, No 2, November 2019

different culure type dimensions relate to perceived work-related stress. Team culture type was a significant negative predictor of perceived stress $(\beta=-0,32, t(254)=44,04 ; p$ $<0,01)$. Participants with higher scores on perceived team culture showed lower levels of workplace stress. $(R 2=0,11 ; F(1,254)=29,86 ; p<0,01)$

\subsection{Study 2}

The second study also focused on the impact of organizational culture on employees' experiences at, and attitudes towards, the workplace. However, this study was targeted at a specific industry (information technology) where employee retention and satisfaction, and organizational identification are key factors in business success due to the high levels of labour shortage.Employee turnover is a particularly sensitive issue in this sector, since new employees usually need to be trained to fulfil the specific requirements related to the job and the target market. Employees who change companies within a short time practically transfer the assets invested in their training to the competition. For this reason, business success is clearly related to the time and energy invested in employees' identification and satisfaction with the organization.

Employees $(n=112)$ from 8 Hungarian IT companies completed a questionnaire battery measuring demographics, perceived organizational culture, organizational identification, and turnover intention. Based on previous findings, the hypotheses of the present study are focused on the relationship between two aspects of organizational culture and employee well- being, namely, identification and turnover intention.

\subsubsection{Hypotheses}

- S2H1: Employees working for an organization with a team culture show higher levels of identification with the organization than those working in other types of culture.

- S2H2: Employees working for an organization with a team culture show lower levels of turnover intention than those working in other types of culture.

\subsubsection{Sample}

A total of 112 employees from Hungarian IT companies participated in the study. Of the overall sample, $82,1 \%(n=92)$ were males and $17,9 \%(n=20)$ were females. Participants' age ranged from 21 to 55 years $(M=33,4)$. By position, most participants including 73 men and 19 women (82.1\%) worked as subordinates, while 10 men and 1 woman worked as middle managers $(9.8 \%)$ and 9 men as senior managers $(8.0 \%)$. 


\section{Journal of International Cooperation and Development}

www.richtmann.org/journal

Vol 2, No 2, November 2019

\subsubsection{Procedure}

An online questionnaire was administered to adult employees who were employed at the time of data collection at an IT company.

\subsubsection{Instruments}

Besides the demographics and OCAI questionnaire described under Study 1, we used a measure of organizational identification and a measure of turnover intention.

Aron and colleagues (1991) operationalized group identification as the perceived overlap between the group and the self. The larger the overlap, the stronger the identification. Their instrument measures the strength of identification by means of Venn diagrams (7 pairs of circles). That is, identification is practically measured by a graphical representation of the perceived overlap between the organization and the self. Respondents are requested to mark the pair of circles which best reflects the extent to which they identify with their organization. Each pair of circles is assigned to one point of a 7-point scale ranging from 1 to 7. The lowest level of identification is represented by the first pair of circles corresponding to 1 on the scale, while the highest level of identification is represented by the seventh pair of circles assigned to 7 . This measure is often used to assess identification with one's organization and other groups (Tropp \& White, 2000).

The validated short version of the Turnover Intention Scale (TIS-6; Bothma \& Roodt, 2013) consists of 6 items, which assess employees' intention to leave or stay at their current organization. Respondents rate each Likert item on a 5-point scale according to the extent to which they agree with the item.

\subsubsection{Results}

Independent samples $t$-tests were conducted to compare mixed employees and IT employees for their OCAI scores, which revealed differences in the distribution of various types of perceived culture. IT employees scored significantly higher on team culture $(M=218.3)$ than mixed employees $(M=181.2 ; t(111)=-3.837, p=.000)$. Similarly, IT employees scored significantly higher on adhocracy $(M=153.2)$ than mixed employees $(M=92.09 ; t(111)=-10.222, p=.000)$. No significant difference was found in the perceived level of market culture $(t(111)=-0.350, p=.727)$. Perceived hierarchy also showed a highly significant difference, on which IT employees scored lower ( $\mathrm{M}=$ 106.5) than mixed employees $(M=200.7 ; t(111)=-14.060, p=.000)$.

In sum, the findings showed that mixed employees and IT employees perceived different organizational cultures. IT employees reported a much higher level of team culture at their companies as compared to mixed employees. 


\section{Journal of International Cooperation and Development}

www.richtmann.org/journal

Vol 2, No 2, November 2019

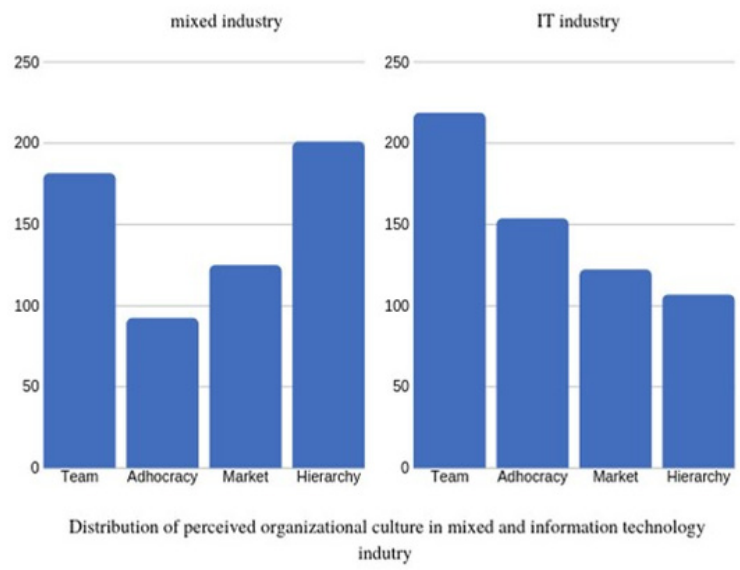

\subsection{Perceived organizational culture and identification}

A Kruskal-Wallis test was conducted to test the effect of organizational culture on organizational identification, since the result of Levene's test indicated that the data did not meet the assumption of homogeneity of variance $(p=.007)$. The results revealed significant differences in organizational identification between the groups with different dominant cultures $(F(3,112)=11.408, p=.01)$. The post hoc pairwise comparisons of the Kruskal-Wallis test indicated that the team culture was associated with significantly higher levels of organizational identification than adhocracy $(p=.034)$, the market culture $(p=.046)$, and hierarchy $(p=.011)$.

These results confirmed the hypothesis on organizational identification and corroborated previous findings on the protective function of the team culture.

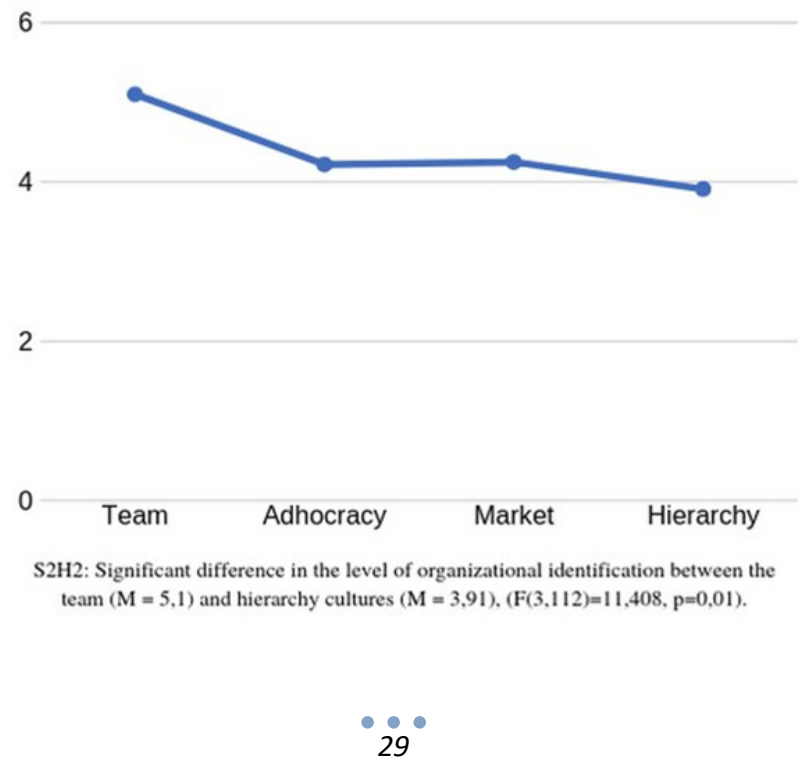




\section{Journal of International Cooperation and Development}

www.richtmann.org/journal

Vol 2, No 2, November 2019

\subsection{Organizational culture and turnover intention}

Since the data did not meet the assumption of homogeneity of variance, a Kruskal-Wallis test was conducted with organizational culture as the independent variable and turnover intention as the dependent variable. The results showed significant differences in turnover intention between the groups with different dominant cultures $(F(3,112)=$ $10.625, p<.05)$.

The post hoc pairwise comparisons of the Kruskal-Wallis test indicated that the team culture was associated with significantly lower levels of turnover intention ( $M=$ 9.6 on a scale ranging from 6 to 30$)$ than hierarchy $(M=15.0 ; p=.004)$. Adhocracy was associated with 12.2 and the market culture with 13.5 on average. No significant differences were found for these cultures.

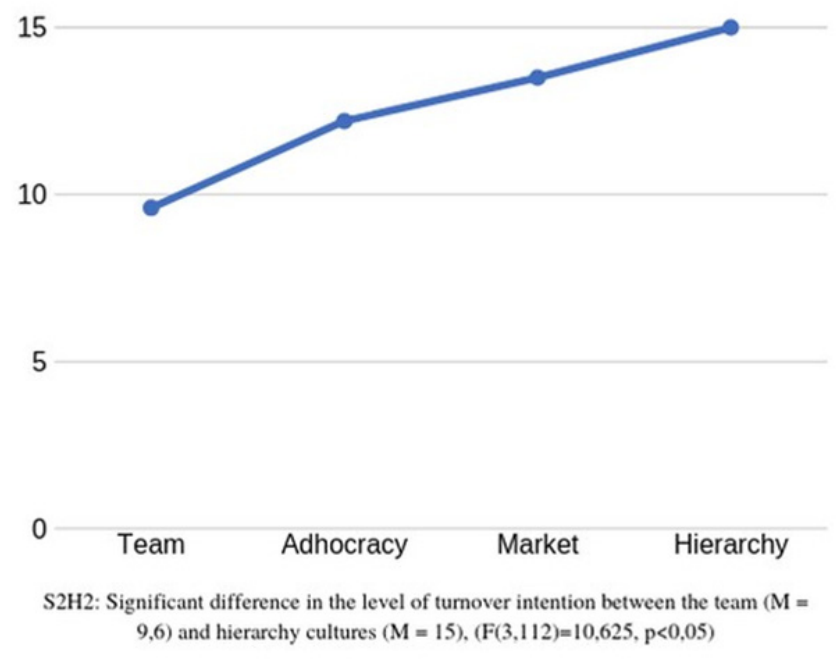

The results suggest that long-term employee commitment is least likely at highly hierarchical organizations. This finding is consistent both with the above mentioned results and with previous related findings (Daulatram, 2003; Reis, Trullen, \& Story, 2016).

Table 2 showes the decriptives, reliabilities and correlations between OCAI scales, organizational identification and turnover intention. Linear regression analyses were used to investigate how the scores on different culure type dimensions relate to organizational identification and turnover intention. Hierarchical culture type was a significant negative predictor of organizational identification. $(R 2=0,13 ; F(1,110)=$ $16,12 ; p<0,01)$ Participants with higher scores on perceived hierarchy culture showed lower scores on organizational identification. $(\beta=-0,36, t(110)=4,02 ; p<0,01)$ Turnover intention was significantly predicted by scores on team and adhocracy scales 
of the CQ. $(R 2=0,23 ; F(1,110)=16,28 ; p$

$<0,01)$ Participants who perceived their workplace as a team $(\beta=-0,46, t(110)=-$ $5,39 ; p<0,01)$ and adhocracy $(\beta=-0,23, t(110)=-2,72 ; p<0,05)$ showed lower level of turnover intention.

\begin{tabular}{|l|l|l|l|l|l|}
\hline $\begin{array}{l}\text { Culture type } \\
\text { (OCAI) }\end{array}$ & M & SD & $\begin{array}{l}\text { Cronbach's } \\
\text { alpha }\end{array}$ & $\begin{array}{l}\text { Pearson's } \\
\text { correlation } \\
\text { with } \\
\text { organizational } \\
\text { identification }\end{array}$ & $\begin{array}{l}\text { Pearson's } \\
\text { correlation } \\
\text { with } \\
\text { turnover } \\
\text { intention } \\
\text { (TIS-6) }\end{array}$ \\
\hline Team & 218.36 & 102.51 & .86 & $.36^{* *}$ & $-.42^{* *}$ \\
\hline Adhocracy & 153.21 & 63.29 & .69 & .06 & -.16 \\
\hline Market & 121.92 & 78.31 & .79 & $-.20^{*}$ & $.35^{* *}$ \\
\hline Hierarchy & 106.21 & 71.33 & .75 & $-.36^{* *}$ & -.36 \\
\hline
\end{tabular}

2. Table: Descriptive statistics, reliabilities and correlations between the variables in Study 2

\section{Conclusions}

The findings of the present study confirmed the hypothesis, which predicted significant differences between different types of organizational culture in employees' perceived stress, organizational identification and turnover intention.

A more detailed analysis of the data revealed that the observed effect on perceived stress was primarily related to the flexibility axis of the value-based model of organizational culture. Both hierarchic and market cultures are characterized by low levels of flexibility and high levels of control. The results suggest that a team culture is the most likely to provide protective factors that reduce the level of stress perceived by employees. Regression analysis also supports this findings, participants with higher scores on perceived team culture showed lower levels of workplace stress. An other result of our Study 2 supports the importance of flexibility. The team and adhocracy culture was associated with significantly lower levels of turnover intention.

It has to be noted that the results do not by any means reflect any differences between the different types of organizational culture in terms of productivity or desirability. Nevertheless, the results are in line with previous findings showing that employees working in a team culture reported higher levels of satisfaction and identification with the workplace.

Irrespective of the pursued activities, it is recommendable for organizations to adopt elements of a team culture, since actual organizational cultures always combine elements of different types. Certain characteristics of a perceived team culture can contribute to the prevention of harmful levels of work-related stress, thus they support employees in successful coping and in achieving and maintaining mental health. Most authors point out the importance of community, social support and job security as the primary factors underlying this protective effect (La Rocco et al., 1980; Shortell et 


\section{Journal of International Cooperation and Development}

www.richtmann.org/journal

Vol 2, No 2, November 2019

al. 2000; Glazer, 2001; Heaphy \& Dutton, 2008; Pow et al., 2017). Further related research is in progress, which is aimed at revealing those characteristics of team cultures that essentially contribute to the prevention of harmful levels of work-related stress, thus they support employees in successful coping and in achieving and maintaining mental health.

Another important finding concerning team cultures is that IT employees perceived a much higher level of team culture at their companies as compared to mixed employees. This finding suggests that the increasing dominance of the IT industry is accompanied by an increasing need for the benefits of a team culture and for certain underlying values. As we can see from the analyses, the level of turnover intention is lower in team and adhocracy, than in other types of culture. With autonomy and flexibility IT employees are planning for longer term. This findig supports other studies, which shows strong relation between team and adhocracy cultures and job satisfaction (Lund, 2003).

Regression analysis of the four culture types and organization identification raise our attention to the risky effect of perceived hierarchy and authority on workplaces. We can see that hierarchical culture type was a significant negative predictor of organizational identification.

Research on the IT industry has particular importance due to the increasing market demand for IT services and their role in national economies. The requirement of efficiency also motivates companies to develop an operational framework that enables them to meet market participants' and employees' needs. Future studies should focus on the characteristics of fast- growing industries, given the ever increasing labour demands in these industries. Beyond meeting basic hygiene requirements, organizational culture is becoming a key factor in labour attraction and retention.

Certain characteristics of a perceived team culture can contribute to the prevention of harmful levels of work-related stress, thus they support employees in successful coping and in achieving and maintaining mental health. Higher level of flexibility can effect lower lever of turnover intention. In the other hand, certain characteristics of a perceived hierarchy culture can be risky in relation with the organizational identification. All these three aspects are important in labour attraction and retention, especially in the IT industry.

\section{Acknowledgement}

The project has been supported by the European Union, co-financed by the European Social Fund (EFOP-3.6.1.-16-2016-00004 - Comprehensive Development for Implementing Smart Specialization Strategies at the University of Pécs) 


\section{Journal of International Cooperation and Development}

www.richtmann.org/journal

Vol 2, No 2, November 2019

\section{References}

Aamodt, M. (2012). Industrial/organizational psychology: An applied approach. Cengage Learning

Barnett, R., \& Gareis, K. (2007). Shift work, parenting behaviors and child socio-emotional wellbeing: A within family study. Journal of Family Issues, 28, 727-748.

Bass, B.M., Avolio, B.J. and Atwater, L. (1996). The transformational and transactional leadership of men and women. Applied Psychology: An International Review, 45, 5-34.

Cornia, Giovanni \& Paniccia, Renato. (2000). The Transition Mortality Crisis: Evidence, Interpretation and Policy Responses.

Cooke, R.A. and Szumal, J.L. (2013). Handbook of Organizational Culture and Climate. Sage Publications pp. 147-162

Denison, D.R., \& Spreitzer, G. M. (1991). Organizational culture and organizational development: A competing values approach. Research in Organizational Change and Development, 5, 121.

De Vries, R. E., van den Hooff, B., \& de Ridder, J. A. (2006). Explaining Knowledge Sharing. Communication Research, 33(2), 115-135.

Daulatram B. Lund, (2003). Organizational culture and job satisfaction, Journal of Business \& Industrial Marketing, Vol. 18 Issue: 3, pp.219-236,

European Agency for Safety and Health at Work (2014). Calculating the cost of work- related stress and psychosocial risks. ISSN: 1831-9351

Faragher, E. B., Cass, M., \& Cooper, C. L. (2005). The relationship between job satisfaction and health: a meta-analysis. Occupational and environmental medicine, 62(2), 105-112.

Ferrie, J. E., Kivimäki, M., Shipley, M. J., Davey Smith, G., \& Virtanen, M. (2013). Job insecurity and incident coronary heart disease: The Whitehall II prospective cohort study. Atherosclerosis, 227(1), 178-181.

Fletcher, B. C. (1988). Occupation, marriage and disease-specific mortality. Social Science and Medicine, 77, 615-622.

Gerdi Weidner, Virginia S. Cain (2003). The Gender Gap in Heart Disease: Lessons From Eastern Europe. American Journal of Public Health 93, no. 5., pp. 768-770.

Germano Reis, Jordi Trullen, Joana Story, (2016) Perceived organizational culture and engagement: the mediating role of authenticity. Journal of Managerial Psychology, Vol. 31 Issue: 6, pp.1091-1105

Hartley, Jean; Jacobson, Dan; Klandermans, Bert and Van Vuuren, Tinka (1990). Job Insecurity: Coping with Jobs at Risk. London: Sage Publications Ltd.

Hellriegel, D., \& Slocum, J. W. (1974). Organizational climate: Measures, research and contingencies. Academy of Management Journal, 17(2), 255-280.

Herzberg, F. (2005). Motivation-hygiene theory. Organizational behavior one: Essential theories of motivation and leadership, eds JB Miner, ME Sharpe Inc, New York, 61-74.

Janna P. O. (2016). Organizational culture and its relationship with employee stress, productivity, and enjoyment of work. University of Northern British Columbia

Jae San Park, Tae Hyun Kim, (2009). Do types of organizational culture matter in nurse job satisfaction and turnover intention? Leadership in Health Services, Vol. 22 Issue: 1, pp.20-38,

Kane-Urrabanzo, C (2006). Management's role in shaping organizational culture. Journal of Nursing Management, 14, 188-194. 


\section{Journal of International Cooperation and Development}

www.richtmann.org/journal

Vol 2, No 2, November 2019

Kiss T., Polonyi T., Imrek M. (2018). Munkahelyi stressz és egészség. A burnout- szindróma a 21. században - kutatás, mérés, elmélet és terápia. Alkalmazott Pszichológia 18(2): 75-103

Kopp Mária S. - Réthelyi J. (2004). Where Psychology Meets Physiology: Chronic Stress and Premature Mortality - The Central-Eastern European Health Paradox. Brain Research Bulletin. 62, 2, 351-367.

Kopp M, Skrabski A, Szanto Z, Siegrist J. (2006): Psychosocial determinants of premature cardiovascular mortality differences within Hungary, Journal Of Epidemiology And Community Health 60: (9) pp. 782-788.

Kopp Mária. S., Skrabski, Á. , Székely, A. , Stauder, A. and Williams, R. (2007). Chronic Stress and Social Changes. Annals of the New York Academy of Sciences, 1113: 325-338.

Kowalski C., Ommen O., Driller E., Ernstmann N., Wirtz M.A., Kohler T. \& Pfaff H. (2010). Burnout in nurses -the relationship between social capital in hospitals and emotional exhaustion. Journal of Clinical Nursing 19(11-12), 1654-1663.

Kivimäki M., Siegrist J. (2016). Work Stress and Cardiovascular Disease: Reviewing Research Evidence with a Focus on Effort-Reward Imbalance at Work. In: Siegrist J., Wahrendorf M. (eds) Work Stress and Health in a Globalized Economy. Aligning Perspectives on Health, Safety and Well-Being. Springer, Cham

Lamb, S., \& Kwok, K. C. S. (2016). A longitudinal investigation of work environment stressors on the performance and wellbeing of office workers. Applied Ergonomics, 52, 104-111.

Lastovkova, A., Carder, M., Rasmussen, H. M., Sjoberg, L., Groene, G. J., Sauni, R.,Pelclova, D. (2017). Burnout syndrome as an occupational disease in the European Union: an exploratory study. Industrial health, 56(2), 160-165.

LaRocco, J. M., House, J. S., \& French, J. R. P. (1980). Social Support, Work-related stress, and Health. Journal of Health and Social Behavior, 21(3), 202.

Mäkikangas, A., Kinnunen, U., Feldt, T., \& Schaufeli, W. (2016). The longitudinal development of employee well-being: a systematic review. Work \& Stress, 30(1), 46-70.

Marmot, M. G.; Rose, G.; Shipley, M.; Hamilton, P. J. (1978). Employment grade and coronary heart disease in British civil servants. Journal of Epidemiology and Community Health. 32(4): 244-249.

Marquez, P. V., \& Saxena, S. (2016). Making Mental Health a Global Priority. Cerebrum : the Dana forum on brain science, 2016, cer-10-16.

McGregor D. (1960). The human side of enterprise. New York: McGraw Hill

Meslé F. (2004). Mortality in Central and Eastern Europe: long-term trends and recent upturns.Demographic research. Special Collection 2. 28 p.

Olson, D. H., Stewart, K. L., Wilson, L. R. (1991): Coping and Stress Profile (CSP). Minneapolis, MN: Life Innovation

OCAI Online (2012). Report: Organizational culture assessment instrument. Public administration. Retrieved from: www.ocai-online.com

Peterson, M. \& Wilson, J. F. (2002). The culture-work-health model and work stress. American Journal of Health Behaviour, 26(1), 16-24.

Pow, J., King, D. B., Stephenson, E., \& DeLongis, A. (2017). Does social support buffer the effects of work-related stress on sleep quality among paramedics? A daily diary study. Journal of Occupational Health Psychology, 22(1), 71-85. 


\section{Journal of International Cooperation and Development}

www.richtmann.org/journal

Vol 2, No 2, November 2019

Probst, T. M., \& Lawler, J. (2006). Cultural Values as Moderators of Employee Reactions to Job Insecurity: The Role of Individualism and Collectivism. Applied Psychology, 55(2), 234-254.

Rahman, Md. Mostafizur \& Sultana, A \& Kabir, Md. (2015). Organizational culture and job satisfaction in the banking sector of bangladesh. 9. 1-6.

Renee Baptiste, N. (2008). Tightening the link between employee wellbeing at work and performance. Management Decision, 46(2), 284-309.

SELYE H. (1950). Stress and the general adaptation syndrome. British medical journal, 1(4667), 1383-1392.

Schein, E. H. (1975). In defense of theory Y. Organizational Dynamics, 4(1), 17-30.

Sherman, S. G., Leahy, M. J., Del Valle, R., Anderson, C. A., Tansey, T. N., \& Lui, K. (2014). Organizational and cultural factors that promote creative best practices in the public rehabilitation program: Findings from a four-state multiple case study. Journal of Vocational Rehabilitation, 41(2), 115-125.

Shortell, S. M., Jones, R. H., Rademaker, A. W., Gillies, R. R., Dranove, D. S., Hughes, E. F., et al. (2000). Assessing the impact of total quality management and organizational culture on multiple outcomes of care for coronary artery bypass graft surgery patients. Medical Care, 38(2), 207-217

Skrabski, Á. (2003). A társadalmi tőke és a középkorú halálozás összefüggései. Demográfia. Vol. 46, No. 1, pp. 95-103

Terry A. Beehr, , Sharon Glazer, (2001). A cultural perspective of social support in relation to work-related stress, in Pamela L. Perrewe, Daniel C. Ganster (ed.) Exploring Theoretical Mechanisms and Perspectives (Research in Work-related stress and Well-being, Volume 1) Emerald Group Publishing Limited, pp.97 - 142

Wakefield, B. J., Blegen, M. A., Uden-Holman, T., Vaughn, T., Chrischilles, E., \& Wakefield, D. S. (2001). Organizational Culture, Continuous Quality Improvement, and Medication Administration Error Reporting. American Journal of Medical Quality, 16(4), 128-134

World Health Organization (2018). Depression: key facts. http://www.who.int/newsroom/factsheets/detail/depression

World Health Organization (2018). Promoting mental health: concepts, emerging evidence, practice (Summary Report). Geneva: World Health Organization 